\title{
Dynamic Temperature Rise Mechanism and Some Controlling Factors of Wet Clutch Engagement
}

\author{
Zhang Zhigang, ${ }^{1,2}$ Shi Xiaohui, ${ }^{1}$ and Guo Dong ${ }^{1}$ \\ ${ }^{1}$ School of Automobile Engineering, Chongqing University of Technology, Chongqing 400054, China \\ ${ }^{2}$ Key Laboratory of Safety Design and Reliability Technology for Engineering Vehicle, Changsha University of Science \& Technology, \\ Hunan 410114, China \\ Correspondence should be addressed to Zhang Zhigang; 15823986269@163.com
}

Received 21 December 2015; Revised 9 May 2016; Accepted 18 May 2016

Academic Editor: Mohammed Nouari

Copyright (C) 2016 Zhang Zhigang et al. This is an open access article distributed under the Creative Commons Attribution License, which permits unrestricted use, distribution, and reproduction in any medium, provided the original work is properly cited.

\begin{abstract}
The friction transmission model of wet clutch is established to analyze the friction transmission mechanism of its engagement. The model is developed by applying both the average flow model and the elastic contact model between the friction disk and separator plate. The key components during wet clutch engagement are the separator plate, friction disk, and lubricant. The one-dimension transient models of heat transfer in radial direction for the three components are built on the basis of the heat transfer theory and the conservation law of energy. The friction transmission model and transient heat transfer models are coupled and solved by using the Runge-Kutta numerical method, and the radial temperature distribution and their detailed parametric study for the three components are conducted separately. The simulation results show that the radial temperature for the three components rises with the increase of radius in engagement. The changes in engagement pressure, lubricant viscosity, friction lining permeability, combined surface roughness RMS, equivalent elasticity modulus, difference between dynamic and static friction coefficients, and lubricant flow have important influence on the temperature rise characteristics. The proposed models can get better understanding of the dynamic temperature rise characteristics of wet clutch engagement.
\end{abstract}

\section{Introduction}

Wet clutch is one of the most essential elements of automobile transmission system and plays a crucial role in the vehicle starting and shifting process [1]. Wet clutch is used for transmitting engine power to the wheel by mechanical friction between separator plate and friction disk. Consequently, the sliding friction heating is produced on the friction pairs of wet clutch and results in the severe temperature rise and thermal stress in separator plate and friction disk. As a result, high temperature will change the physical features of lubricant and the local thermal ablation on surfaces of separator plate and friction disk and even leads to the crack, warp, and sintering of friction pair and the deterioration of lubricant [2-4].

So far, much research has been carried out in this field, but most of publications only pay attention to analyzing the temperature field and stress field by using the finite element software. For instance, Zagrodzki and Truncone [5] investigated the generation of hot spots during short-term engagement and presented the theoretical analysis based on finite element model of thermoelastic contact problem and experimental stand tests. Their study shows that severe hot spots can be produced during short-term clutch operation with high initial sliding speed and some small geometric imperfections of the disk, and the hot spots can be effectively mitigated even if instantaneous sliding at high speed cannot be avoided. Jen and Nemecek [6] developed an analytical model to simulate the temperature rise of plates within wet clutch for one engagement. And the temperature rises predicted by the model were validated with the experimental data. Tatara and Payvar [7] developed a general thermal numerical model in two dimensions to simulate the heat transfer in a grooved wet clutch and characterized one cycle by three stages including an engagement period, a locked stage, and a cooling period. The finite difference technique was employed to solve the heat conduction equation. Jang et al. [8] developed a model to investigate the effect of radial grooves and waffle-shape grooves on the performance of 
a wet clutch and investigated the effects of groove geometry on the temperature and the engagement characteristics. Yang et al. [9] proposed the research methods of thermomechanical coupling problem of wet multidisc clutch and investigated the thermo-mechanical coupling phenomenon and the failure mechanism of separator plate of wet multidisc clutch. Their results show that the circumferential tensile thermal stress appeared in the region close to the inner edge, and the radial tensile thermal stress appeared in the region close to the outer edge. Zhang et al. $[2,10]$ developed a three-dimensional model of the friction pair by using the nonlinear FEM software ABAQUS and investigated the factors to influence the distribution of temperature field and stress field for one engagement. Results indicated that high relative rotary speed resulted in higher rise of temperature and stress on interior areas and increased the radial stress gradient on the contact surfaces, and the temperature field and stress field on the friction disk were more uniform than those on the steel disk. These previous works achieved certain understanding of the temperature field of wet clutch. Natsumeda and Miyoshi [11] carried out theoretical analysis on the engagement of wet clutch on the basis of two-dimensional average flow model for the analysis of oil film squeeze motion and mainly analyzed the effect of temperature on the frictional torque of wet clutch engagement. However, few studies focus on the dynamic friction thermal mechanism of wet clutch to predict the temperature rise characteristics and controlling factors, which are important for the thermal characteristics of wet clutch.

Therefore, the purpose of this paper is to numerically investigate the friction thermal mechanism in different engagement stages of wet clutch based on the friction transmission mechanism of wet clutch. The friction transmission model and transient heat transfer models are coupled and solved by using the numerical method. Key parametric factors are conducted by the proposed models.

\section{Model Development}

According to the differences of generation mechanisms of the transmitted torque and axial load [9], the engagement of wet clutch is divided into three stages: squeezing fluid stage, boundary lubrication stage, and asperity contact stage. In squeezing fluid stage, engagement pressure is alone borne by oil film, and transmitted torque only consisted of the viscous shear torque of oil film. In boundary lubrication stage, engagement pressure is together borne by the oil film pressure and the asperity contact of friction pair, and transmitted torque involves the viscous shear torque of oil film and the asperity friction torque of friction pair, and with wet clutch engaging, contact and friction of asperities gradually play a dominant role in the formation of pressure and torque. Finally, in asperity contact stage, the asperity contact between friction pairs bears all of the engagement pressure, and transmitted torque is completely composed of asperity friction torque. Friction transmission mechanism of wet clutch is modeled in the following, respectively.

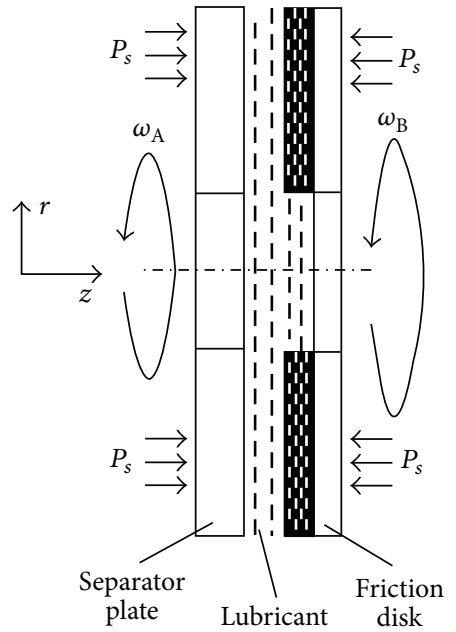

FIGURE 1: Physical model of wet clutch engagement.

2.1. Oil Film Model. The engagement process of wet clutch can be simplified as the physical model shown in Figure 1. Before engagement, the oil film will separate the friction disk and separator plate and perform cooling lubrication on the both. At this time, the angular velocity is $\omega_{\mathrm{A}}$ for the separator plate and $\omega_{\mathrm{B}}$ for the friction disk, and the engagement pressure $P_{s}$ acts on the friction pair. For the reason of simplicity, many reasonable assumptions were proposed in the following analysis. For example, surface of wet clutch friction was assumed to have isotropic roughness and the asperity height was assumed to have a Gaussian distribution. Although these reasonable assumptions would reduce the accuracy of the model, the model could still be used to analyze the controlling factors of temperature in engagement of wet clutch. The one-dimension average flow model of wet clutch lubricant oil film is established under the cylindricalcoordinate system by use of the average flow model $[12,13]$ and in consideration of the axial symmetric characteristics of the friction disk and separator plate:

$$
\frac{\mathrm{d}}{\mathrm{d} r}\left[r \phi_{r}\left(h^{3}+12 \Phi d\right) \frac{\mathrm{d} P_{h}}{\mathrm{~d} r}\right]=12 \eta r \frac{\mathrm{d} \bar{h}_{T}}{\mathrm{~d} t} .
$$

The relation between the average gap $\bar{h}_{T}$ of friction pairs and the oil film thickness $h$ can be obtained by assuming that the surface roughness peaks of both friction disk and separator plate follow the Gaussian probability density distribution with mean value of zero:

$$
\frac{\mathrm{d} \bar{h}_{T}}{\mathrm{~d} t}=\left\{\frac{1}{2}\left[1+\operatorname{erf}\left(\frac{h}{\sqrt{2} \sigma}\right)\right]\right\} \frac{\mathrm{d} h}{\mathrm{~d} t}=g(h) \frac{\mathrm{d} h}{\mathrm{~d} t} .
$$

The boundary condition of oil film pressure is as follows:

$$
\begin{gathered}
P_{h}(r=a)=0, \\
P_{h}(r=b)=0, \\
h(t=0)=h_{0} .
\end{gathered}
$$

By utilizing the boundary conditions of oil film pressure at the inner and outer diameters of friction pair, it can be 
obtained that the oil film pressure distributes along radial direction through integration against $r$ in (1):

$$
\begin{aligned}
P_{h}(r)= & \frac{3 \eta}{\phi_{r}\left(h^{3}+12 \Phi d\right)}\left[r^{2}+\frac{b^{2}-a^{2}}{2 \ln (a / b)} \ln \frac{r}{b}-b^{2}\right] \\
& \cdot g(h) \frac{\mathrm{d} h}{\mathrm{~d} t} .
\end{aligned}
$$

2.2. Asperity Contact Model. The actual contact area $A_{c}$ at the asperity contact part of the wet clutch friction pair can be derived by the use of the G-W elastic contact model under the assumed condition that the surface roughness peak of the wet clutch friction pair follows the Gaussian density function:

$$
\begin{aligned}
& A_{c} \\
& \qquad=\pi \lambda \gamma \sigma\left[\frac{1}{\sqrt{2 \pi}} e^{-(h / \sqrt{2} \sigma)^{2}}+\frac{h}{2 \sigma}\left(\operatorname{erf}\left(\frac{h}{\sqrt{2} \sigma}\right)-1\right)\right] .
\end{aligned}
$$

The asperity contact pressure $P_{c}$ is borne on the unit actual contact area of the wet clutch friction pair:

$$
P_{c}=E \cdot \varepsilon=E \cdot \frac{A_{c}}{\pi\left(b^{2}-a^{2}\right)} .
$$

2.3. Engagement Pressure and Frictional Torque. According to the characteristics of the wet clutch engagement process, the engagement pressure is successively borne by the oil film pressure and asperity contact pressure, and the bearing capacity and transmitted torque composition of the wet clutch are different under different engagement stages; thus, the following can be obtained as per the balance conditions of bearing capacity during engagement process of wet clutch:

$$
\pi\left(b^{2}-a^{2}\right) P_{0}=\iint P_{h} \mathrm{~d} A+\iint P_{c} \mathrm{~d} A .
$$

The following can be obtained in accordance with the transmitted torque composition during the engagement process of wet clutch and in combination with the torque balance conditions during the same process:

$$
I \frac{\mathrm{d} \omega_{\mathrm{rel}}}{\mathrm{d} t}=\iint\left[\left(\phi_{f}-\phi_{f_{s}}\right) \frac{r^{2} \eta \omega_{\mathrm{rel}}}{h}+f_{c} r P_{c}\right] \mathrm{d} A .
$$

\section{Thermal Model of Wet Clutch}

It is known through analysis on friction transmission mechanism of wet clutch that the transmitted torque during the engagement process of wet clutch consists of viscous shear torque of oil film and asperity friction torque of asperity contact and that, with wet clutch engaging, the transmitted torque of wet clutch gradually transitions from complete viscous torque of oil film to complete asperity friction torque of asperity contact. The changes in the transmitted torque composition cause the changes in the friction heat mechanism between friction pairs during the engagement process of wet clutch, that is, gradual transition from sliding friction power of complete viscous shear to sliding friction power of

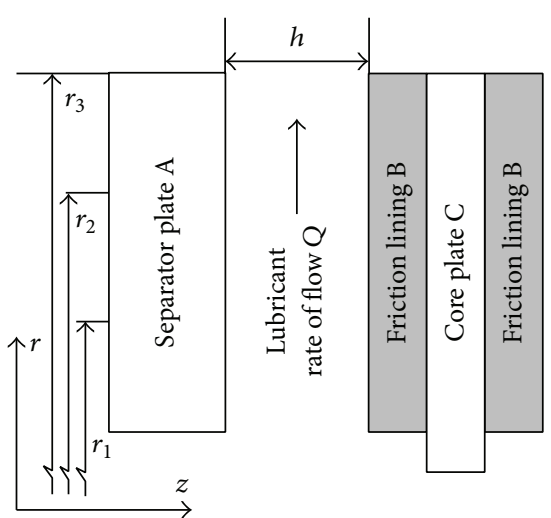

FIGURE 2: Model of thermal analysis for the friction pairs of wet clutch.

complete asperity friction. Therefore, during the engagement process of wet clutch, the heat flux density $q$ between friction pairs is correspondingly composed of the heat flux density of viscous shear and asperity contact friction, which can be indicated as

$$
q=\left[\left(\phi_{f}-\phi_{f_{s}}\right) \frac{r^{2} \eta \omega_{\mathrm{rel}}}{h}+f_{c} r P_{c}\right] \cdot \omega_{\mathrm{rel}} .
$$

During the engagement process of wet clutch, the friction heat generated between friction pairs dissipates on the separator plate, friction disk, and lubricant, which causes temperature rise of the separator plate, friction disk surface, and lubricant. Therefore, the study on the dynamic temperature rise characteristics of wet clutch is mainly to analyze the temperature variation role of the separator plate, friction disk, and lubricant.

To facilitate the analysis and calculation, the following assumptions are made: (1) the thermal radiation effect of friction pair is not taken into account and the heat exchange between separator plate $\mathrm{A}$ and inner and outer cylindrical surfaces of friction lining $B$ is ignored because the engagement time of wet clutch is short; (2) the axial conduction of temperature on the separator plate $A$ and friction lining $B$ is ignored because the both are thin-wall parts; (3) the central plane of core plate $\mathrm{C}$ can be deemed as a thermal isolation plane and the temperature gradient between the friction linings and core plate is ignored because the heat conductivity coefficient of friction linings is relatively small while the heat conductivity coefficient of core plate is relatively large and the core plate is of symmetric structure; (4) only the radial heat conduction of temperature on separator plate and friction disk, heat transfer between friction pairs, and forcedconvection heat transfer on friction surface are considered. Meanwhile, to study the radial temperature distribution role of friction pair, the friction pair is divided equally into 3 zone nodes along radial direction ( $r_{3}$ outer zone, $r_{2}$ middle zone, and $r_{1}$ inner zone), and the average temperature of each zone is taken as the zone node temperature. The simplified model of thermal analysis on wet clutch friction pair is shown in Figure 2. The heat transfer control equations for the separator plate, friction disk, and lubricant in the engagement process 

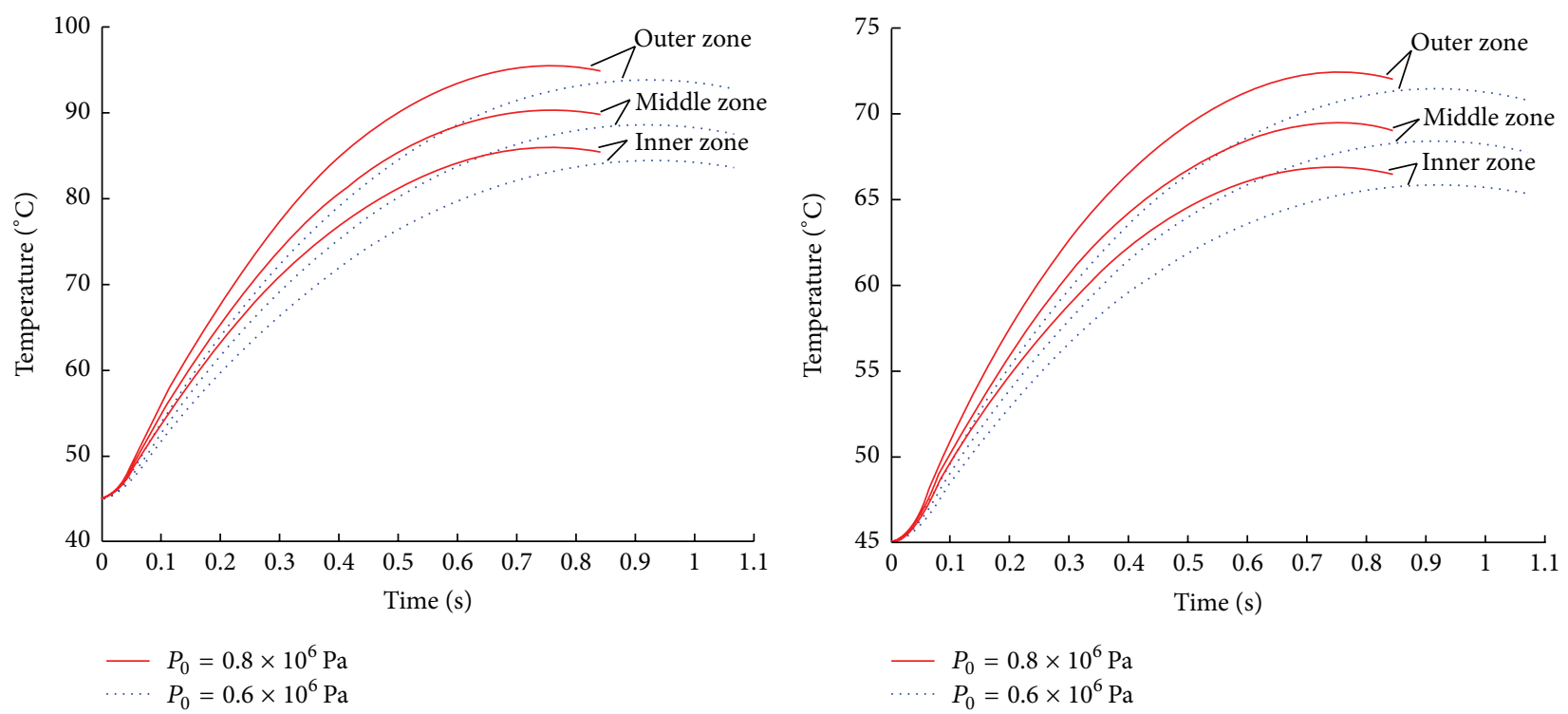

(a) Separator plate

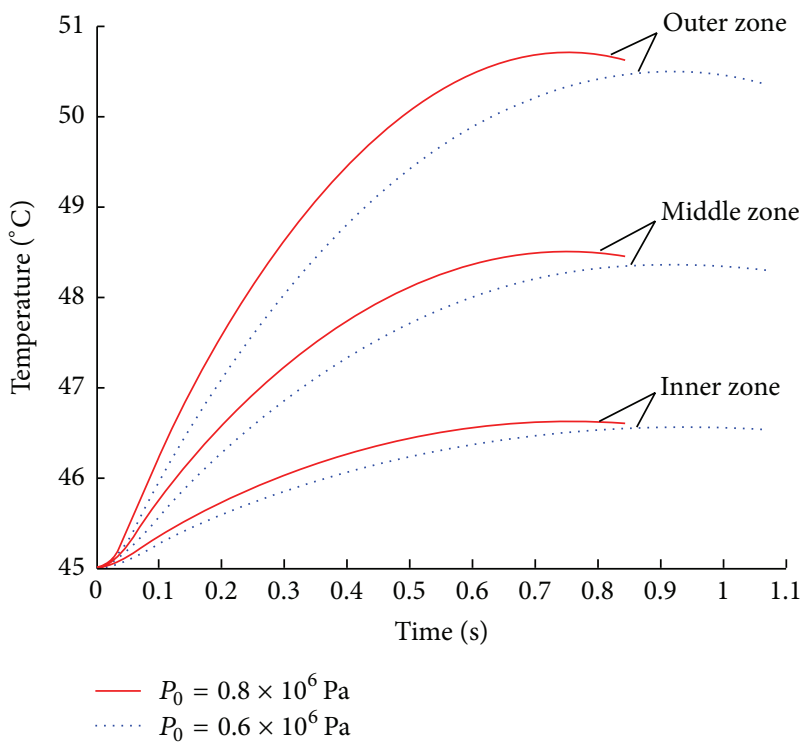

(c) Lubricant

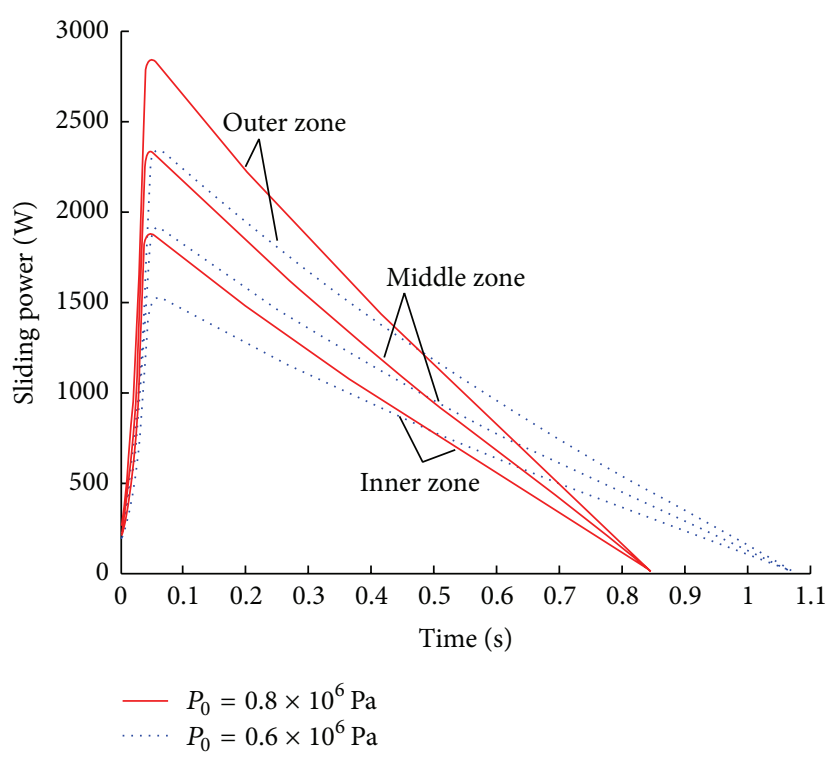

(d) Sliding power

FIGURE 3: Effect of engagement pressure on temperature.

of wet clutch are established, respectively, by the use of the heat transfer theory.

Under the conditions of cylindrical-coordinate system, the one-dimensional transient equation of heat transfer of separator plate A in radial direction can be established:

$$
\rho_{\mathrm{A}} c_{\mathrm{A}} \frac{\mathrm{d} T_{\mathrm{A}}}{\mathrm{d} t}=k_{\mathrm{A}}\left(\frac{1}{r} \frac{\mathrm{d} T_{\mathrm{A}}}{\mathrm{d} r}+\frac{\mathrm{d}^{2} T_{\mathrm{A}}}{\mathrm{d} r^{2}}\right) .
$$

The one-dimensional transient equation of heat transfer of friction disk B in radial direction is established:

$$
\rho_{\mathrm{B}} \mathcal{C}_{\mathrm{B}} \frac{\mathrm{d} T_{\mathrm{B}}}{\mathrm{d} t}=k_{\mathrm{B}}\left(\frac{1}{r} \frac{\mathrm{d} T_{\mathrm{B}}}{\mathrm{d} r}+\frac{\mathrm{d}^{2} T_{\mathrm{B}}}{\mathrm{d} r^{2}}\right) .
$$

During the engagement process of wet clutch, there is forced-convection heat transfer between lubricant and separator plate and friction disk, whose thermal boundary condition can be indicated as

$$
\rho_{\mathrm{o}} c_{\mathrm{o}} \mathrm{Q} \frac{\mathrm{d} T_{\mathrm{o}}}{\mathrm{d} r}=2 \pi r_{p} h_{f}\left[\left(T_{\mathrm{A}}-T_{\mathrm{o}}\right)+\left(T_{\mathrm{B}}-T_{\mathrm{o}}\right)\right]
$$

Because the physical property parameters such as specific heat capacity $c$, density $\rho$, and heat conductivity coefficient $k$ of the separator plate and friction disk are different, the heat generated by friction during the engagement process of wet clutch is not equally distributed between the separator plate and friction disk; the distribution depends on the heat flux distribution coefficient $\rho$ [2] determined by material density 


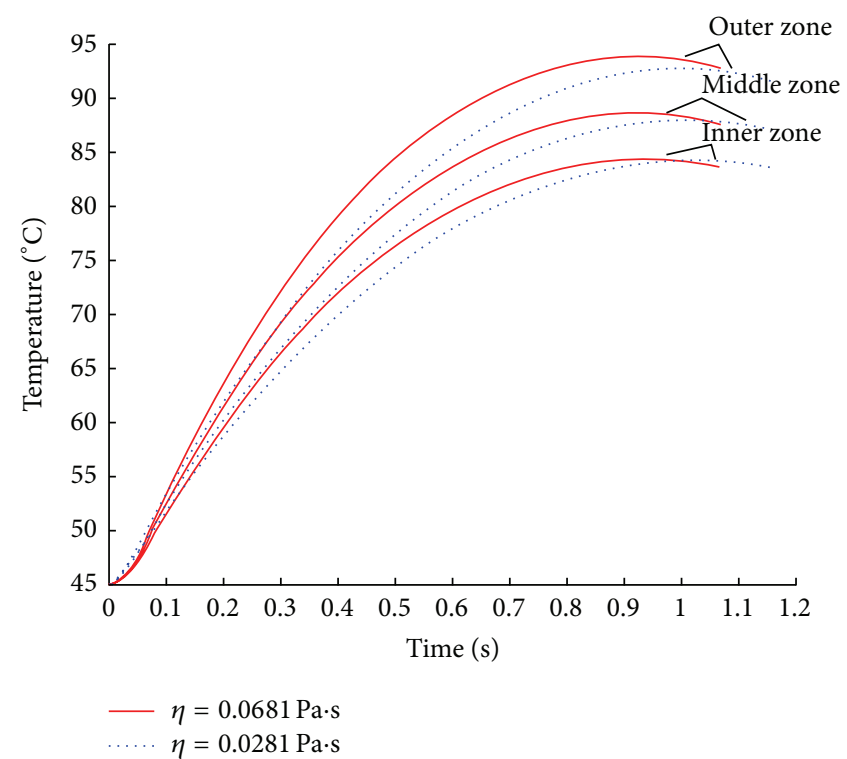

(a) Separator plate

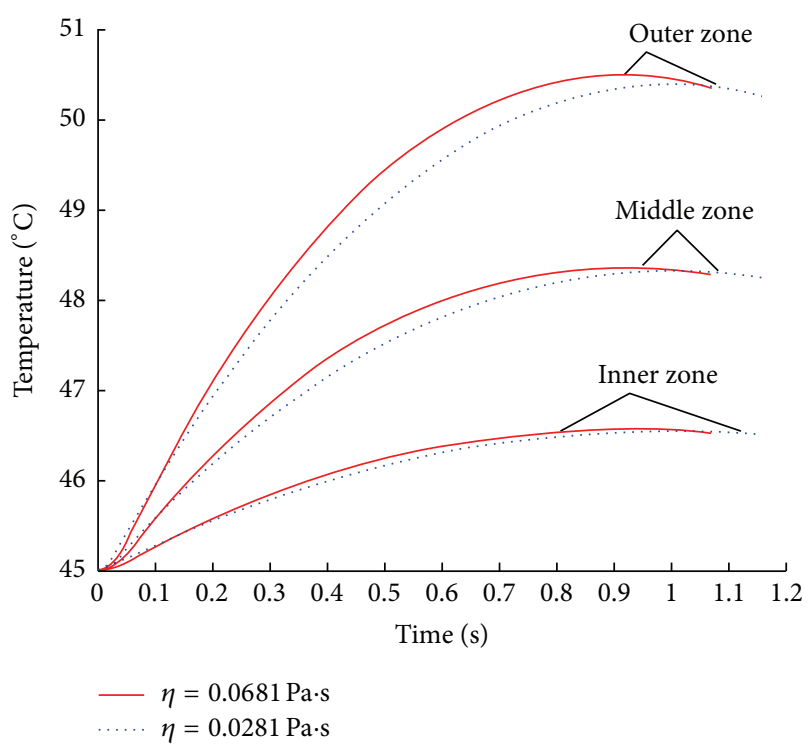

(c) Lubricant

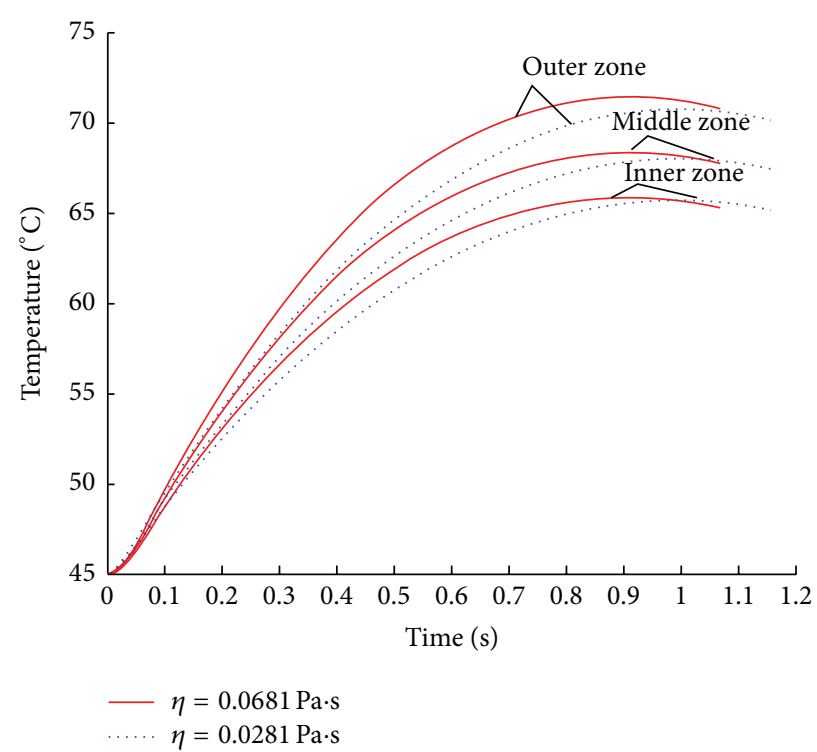

(b) Friction disk

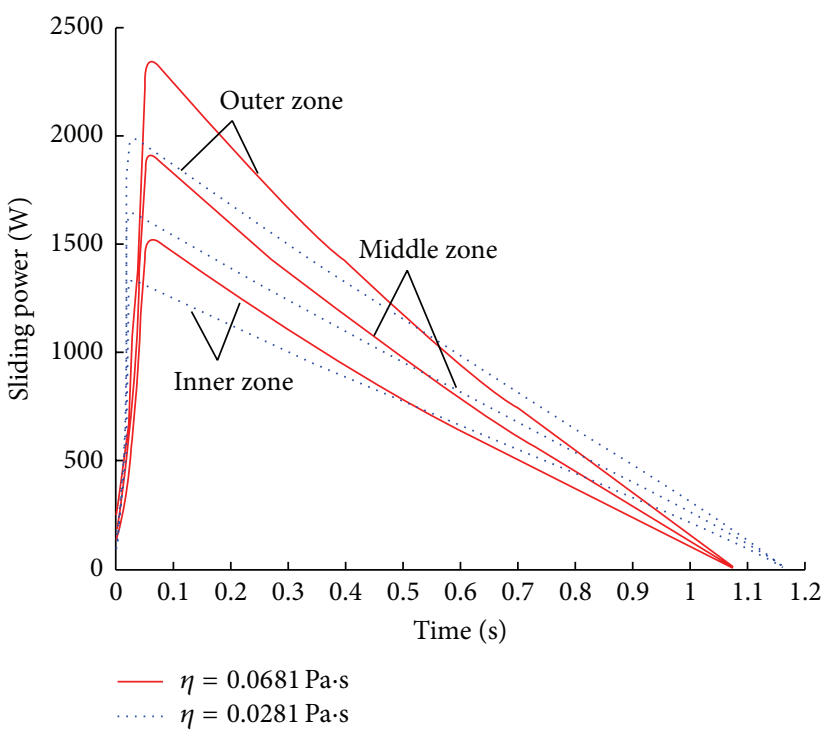

(d) Sliding power

FIGURE 4: Effect of lubricant viscosity on temperature.

$c$, specific heat capacity $\beta$, heat conductivity coefficient $k$, and other parameters:

$$
\beta=\frac{q_{\mathrm{A}}}{q_{\mathrm{B}}}=\left(\frac{k_{\mathrm{A}} \rho_{\mathrm{A}} c_{\mathrm{A}}}{k_{\mathrm{B}} \rho_{\mathrm{B}} c_{\mathrm{B}}}\right)^{0.5} .
$$

The convective heat transfer coefficient $h_{f}$ is affected by many factors such as temperature, pressure, and relative angular velocity during the engagement process. To facilitate the study, only the effect of relative angular velocity $\omega_{\text {rel }}$ is considered herein; thus, the convective heat transfer coefficient [14] can be indicated as

$$
h_{f}=N_{u} k_{f}\left(\frac{\omega_{\text {rel }}}{\eta}\right)^{0.5} .
$$

\section{Results and Discussion}

The Runge-Kutta numerical integration method is used in this paper to calculate numerical integration through combining (4) and (8), by which the oil film thickness $h$ and relative angular velocity $\omega_{\text {rel }}$ of friction pair at each moment can be obtained; the step size for numerical calculation is $0.001 \mathrm{~s}$, and the iteration termination condition is relative angular velocity $\omega_{\text {rel }}=0.001$. The viscous torque $T_{h}$, asperity friction torque $T_{c}$, and total transmitted torque $T$ can be obtained with the oil film thickness and change rate of relative angular velocity; thus, the heat flux density of friction pair at each moment can be gotten by the use of (9). Finally, by using the heat transfer control equations (10), (11), and (12) of wet clutch, the average temperature of 3 zones of separator 

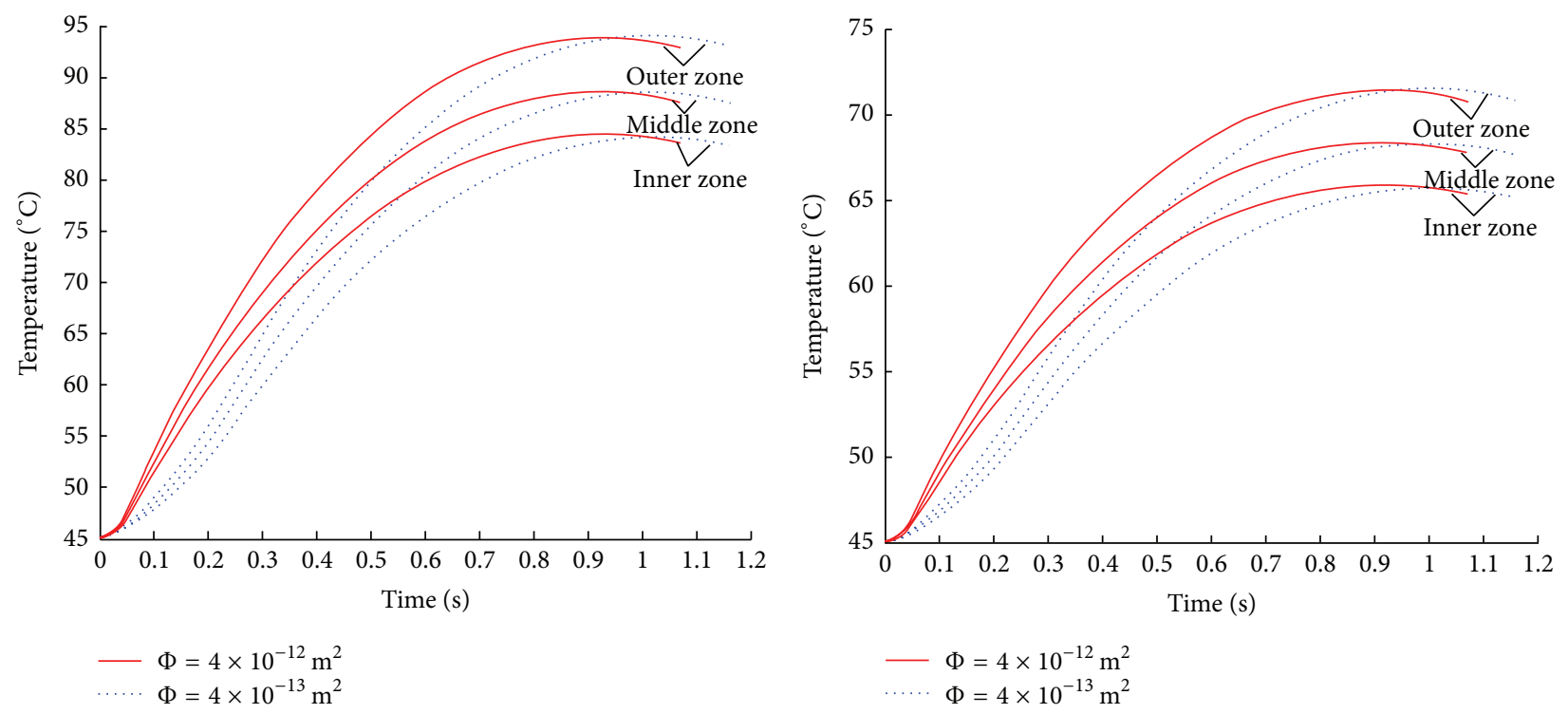

(a) Separator plate
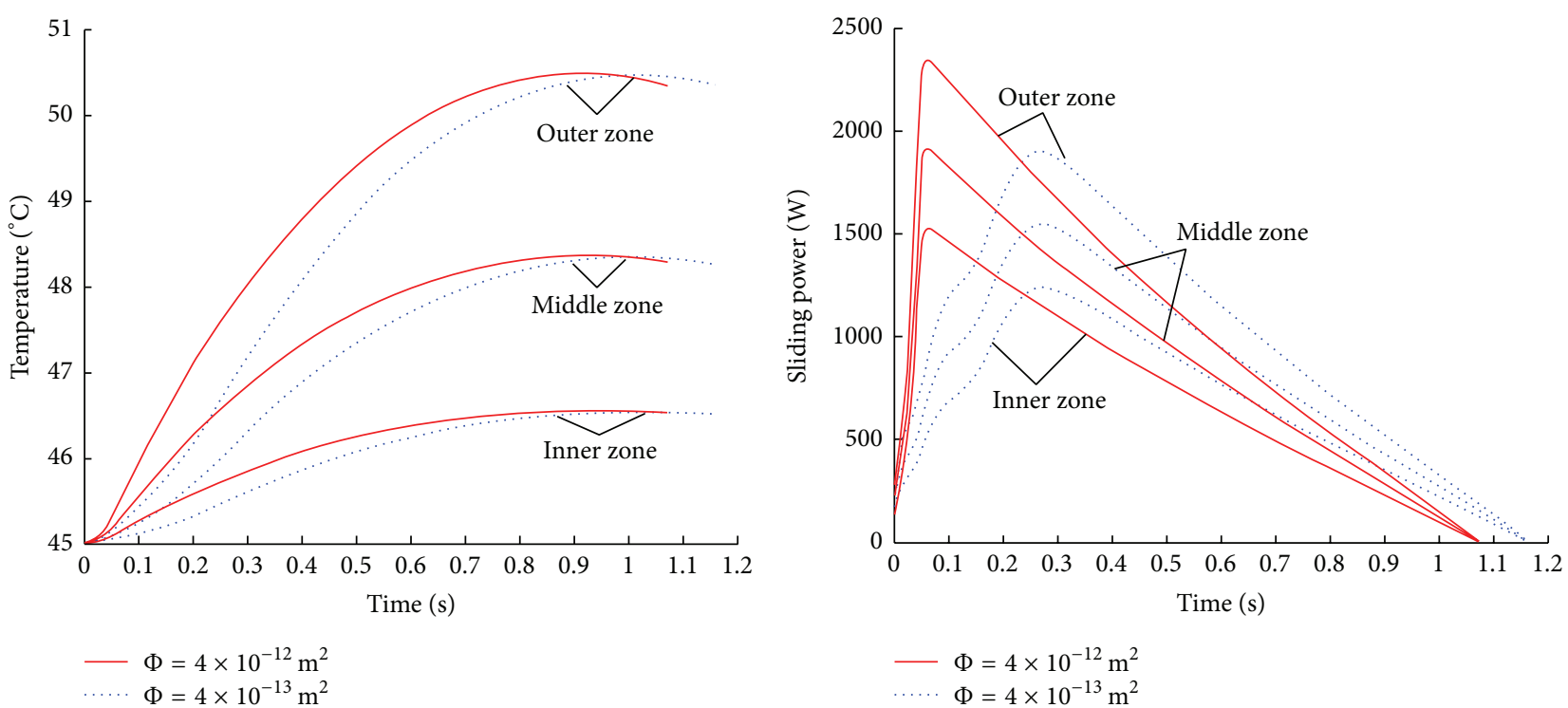

(c) Lubricant

(d) Sliding power

FIGURE 5: Effect of friction lining permeability on temperature.

plate, friction disk, and lubricant during the engagement process of wet clutch can be obtained. If it is assumed that the angular velocity $\omega_{\mathrm{A}}$ of separator plate is zero constantly, the initial angular velocity of friction disk is $\omega_{0}$, the friction disk gradually compresses the separator plate, and the initial temperature of wet clutch is $45^{\circ} \mathrm{C}$ during simulation, the initial condition of simulation is as shown in Table 1.

4.1. Influence of Engagement Pressure. As shown in Figure 3, the engagement pressure directly affects the temperature of friction disk, separator plate, and lubricant. With the increase of the engagement pressure, the engagement time is shortened, and the rise rate and maximum of temperature in each zone of friction pair and lubricant increase. This is because the transmitted torque and heat flux density will be increased along with the increase of engagement pressure. Meanwhile, the engagement time contraction reduces the lubricant volume inflowing to the friction pair and thus increases the temperature of the friction pair and lubricant.

4.2. Influence of Lubricant Viscosity. Figure 4 shows the role of the influence of changes in lubricant viscosity in the temperature rise characteristics of wet clutch. A larger lubricant viscosity will result in a shorter engagement time as well as a higher temperature rise rate and maximum temperature for each zone of friction pair and lubricant. The influence of lubricant viscosity on the outer zone temperature of friction pair and lubricant is more apparent. This is because the viscous shear torque increases at squeezing stage and boundary lubrication stage due to the increase of lubricant 


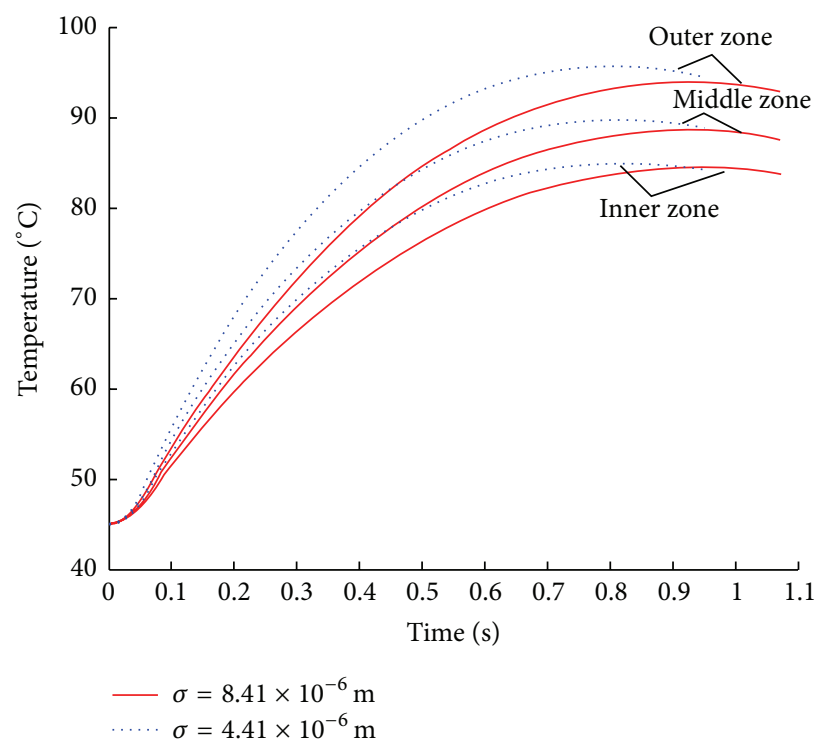

(a) Separator plate

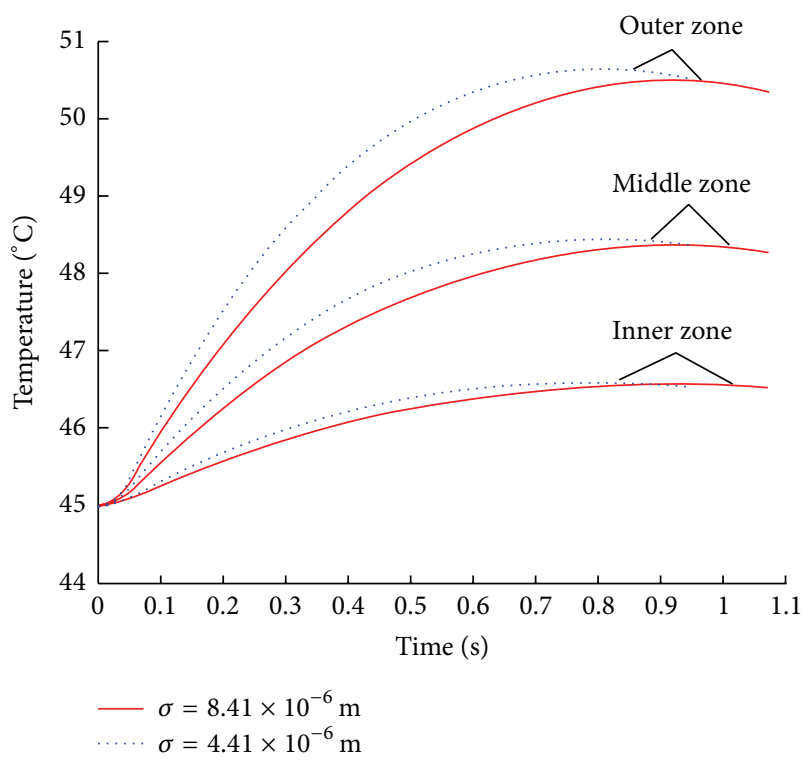

(c) Lubricant

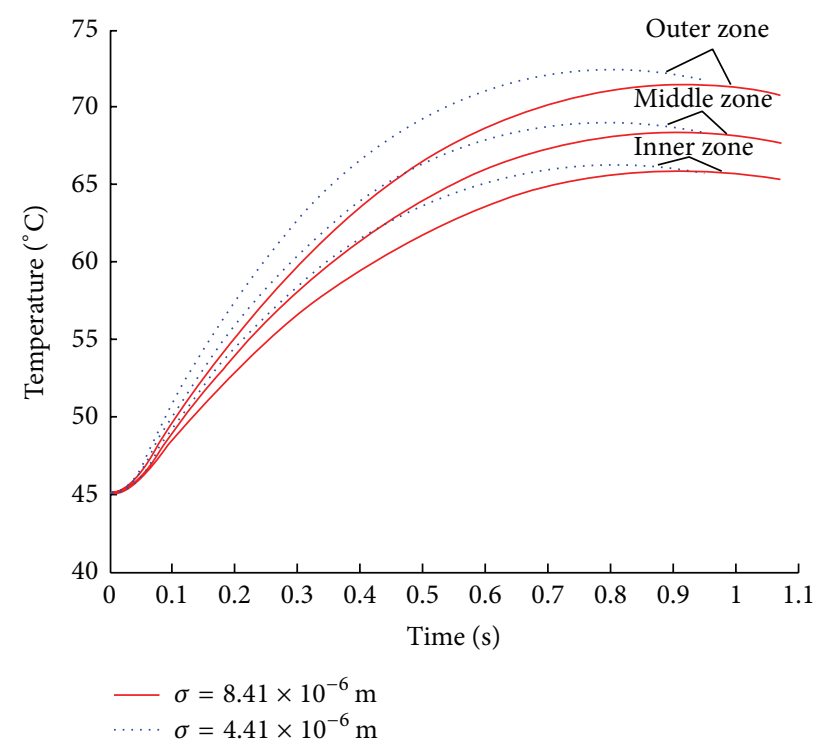

(b) Friction disk

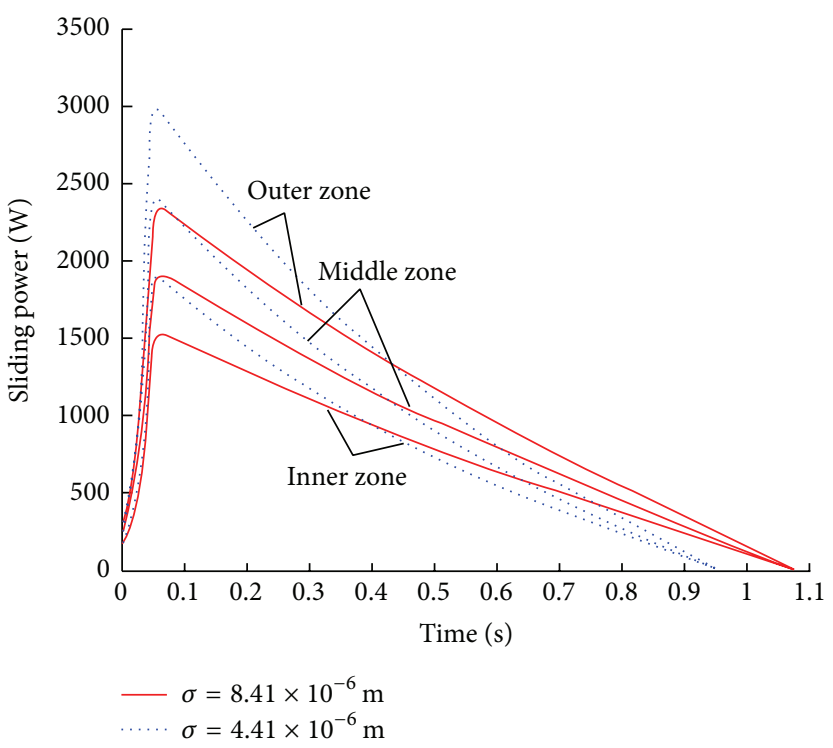

(d) Sliding power

FIGURE 6: Effect of combined surface roughness RMS on temperature.

viscosity and thus the corresponding viscous shear heat flux density increases. Meanwhile, the viscosity of lubricant is relatively large with bad mobility, which further weakens the cooling effect of lubricant.

4.3. Influence of Friction Lining Permeability. As shown in Figure 5, the permeability of friction lining has important influence on the temperature rise characteristics of friction pair and lubricant at the squeezing stage and boundary lubrication stage during engagement of wet clutch. With the increase of friction lining permeability, the temperature rise rate for each zone of friction pair and lubricant increases obviously; however, the influence on the maximum temperature of friction pair and lubricant is relatively small. This is because the lubricant is easier to permeate into cellular structure of friction lining material with the increase of friction lining permeability, which largely shortens the squeezing period, and the friction pair can enter the boundary lubrication stage of heat dissipation mutually by the viscous shear heat flux and asperity friction heat flux more early, which apparently increases the heat generation rate of wet clutch.

4.4. Influence of Combined Surface Roughness RMS. As shown in Figure 6, the larger the combined surface roughness RMS (Root Mean Square) of friction pair is, the longer the engagement time and the smaller the temperature rise rate and maximum temperature of friction pair and lubricant will be. This is because larger combined surface roughness RMS of friction pair will result in rougher surface of friction pair and early contact of individual asperity, which slows down 


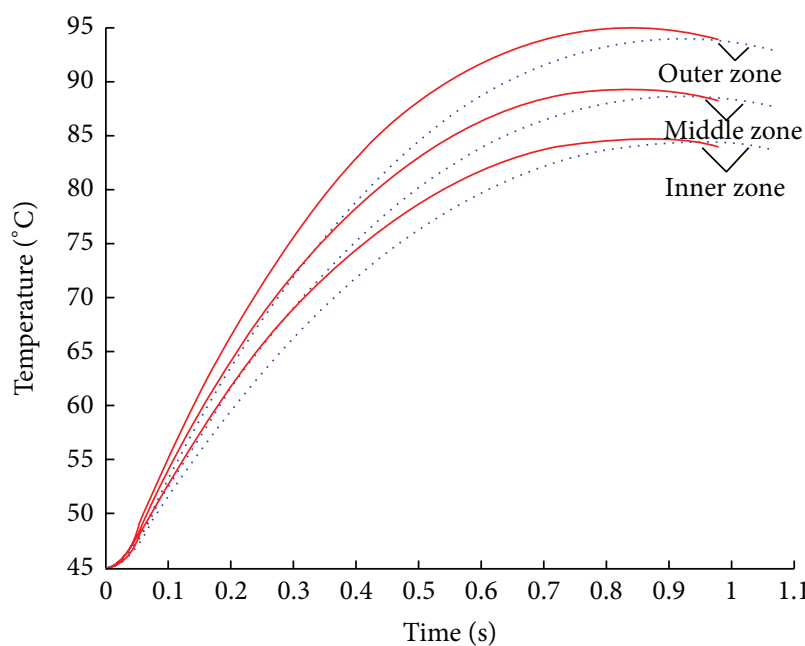

$\begin{aligned} E & =2.7 \times 10^{8} \mathrm{~Pa} \\ E & =2.7 \times 10^{7} \mathrm{~Pa}\end{aligned}$

(a) Separator plate

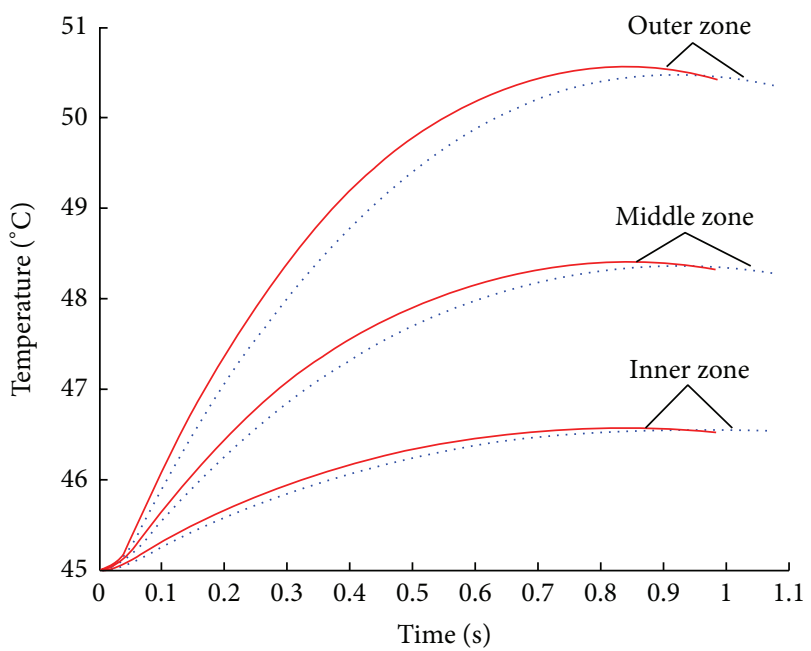

$\begin{aligned} E & =2.7 \times 10^{8} \mathrm{~Pa} \\ \cdots \ldots & E=2.7 \times 10^{7} \mathrm{~Pa}\end{aligned}$

(c) Lubricant

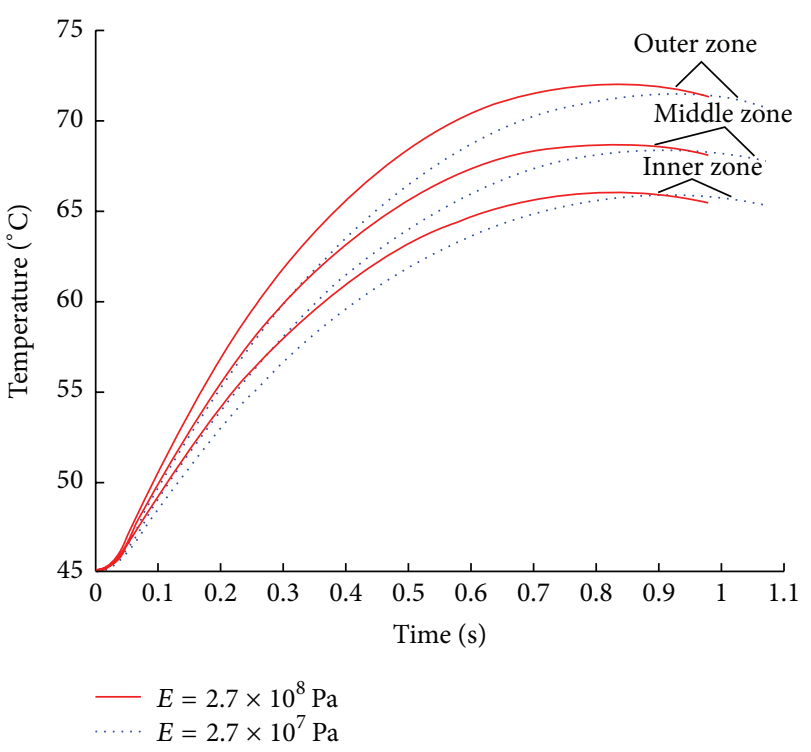

(b) Friction disk

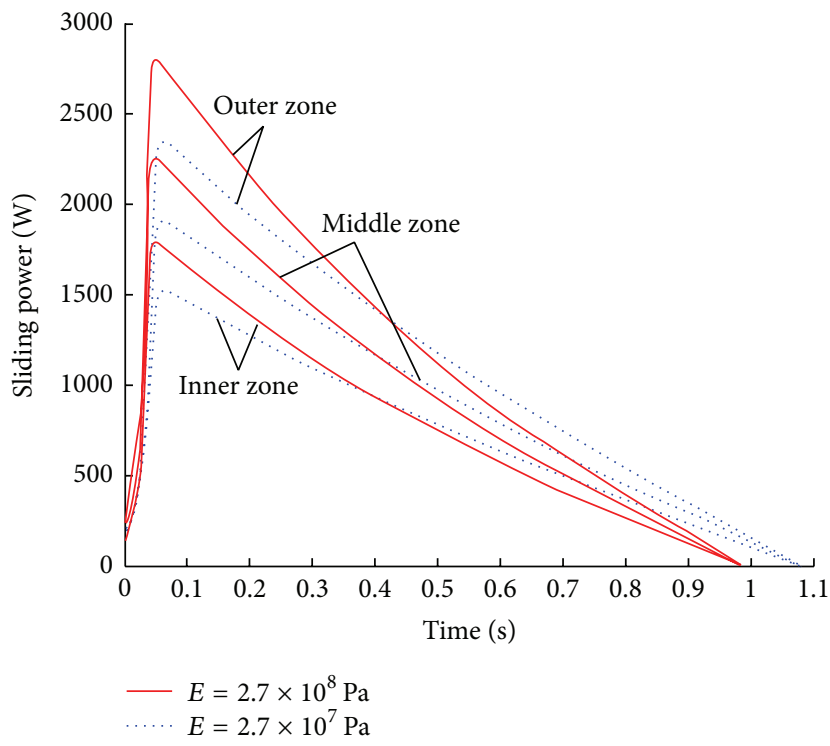

(d) Sliding power

FIGURE 7: Effect of equivalent elasticity modulus on temperature.

the squeezing velocity of lubricant between friction pairs and decreases the viscous shear torque of lubricant. Meanwhile, with the increase of the combined surface roughness RMS of friction pair, the density of asperity contact points on friction pair surface and the asperity friction torque will be smaller, and the increase rate of sliding friction power will be slower.

4.5. Influence of Equivalent Elasticity Modulus. As shown in Figure 7, the larger the equivalent elasticity modulus of friction pair is, the shorter the engagement time and the larger the temperature rise rate and maximum temperature of each zone of friction pair and lubricant will be. This is because of the notion that, with the increase of the equivalent elasticity modulus of friction pair, the asperity friction torque will increase correspondingly and the asperity friction heat flux density will also increase under the same contact conditions of asperity, causing increase in the sliding friction power during engagement of wet clutch. Meanwhile, because the engagement time is shortened, the time of cooling effect of lubricant is also shortened, causing increase of maximum temperature of friction pair and lubricant.

4.6. Influence of Difference between Dynamic and Static Friction Coefficients. Figure 8 shows the influence of the difference between dynamic and static friction coefficients on the temperature rise characteristics of friction pairs and lubricant of wet clutch. As shown in Figure 8, with the decrease of the difference between dynamic and static friction coefficients, the engagement time is shortened, and 


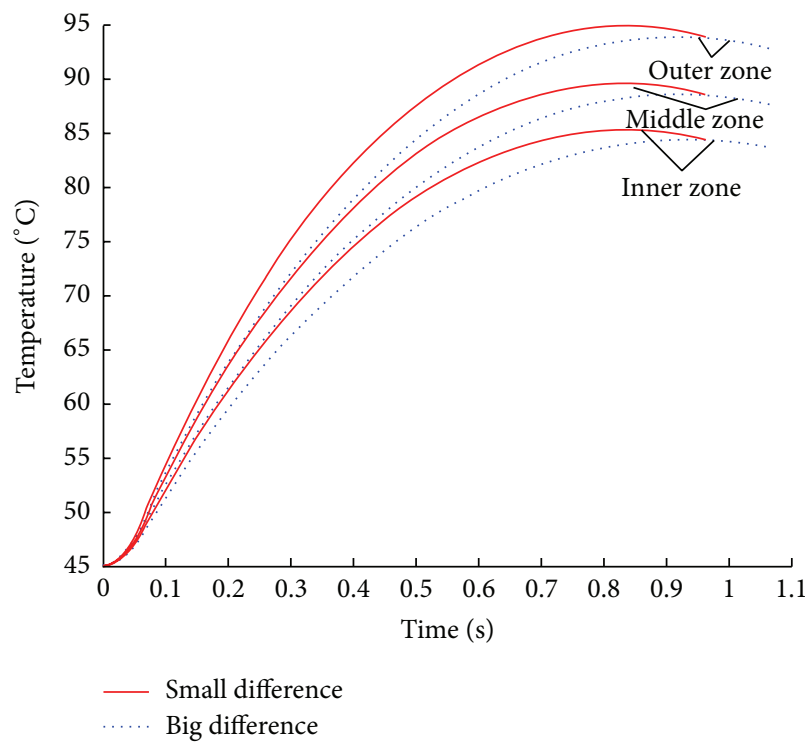

(a) Separator plate

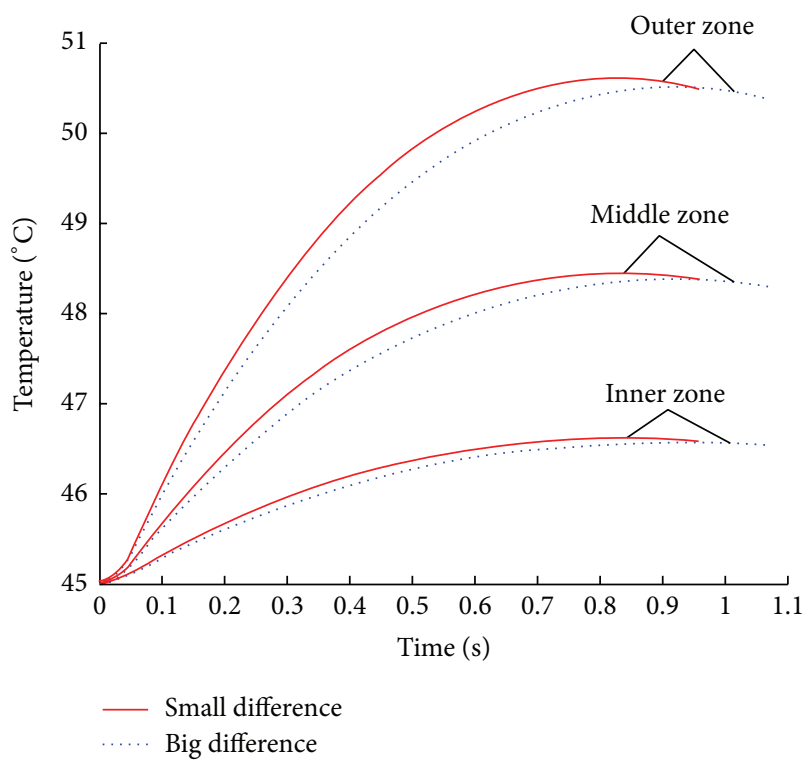

(c) Lubricant

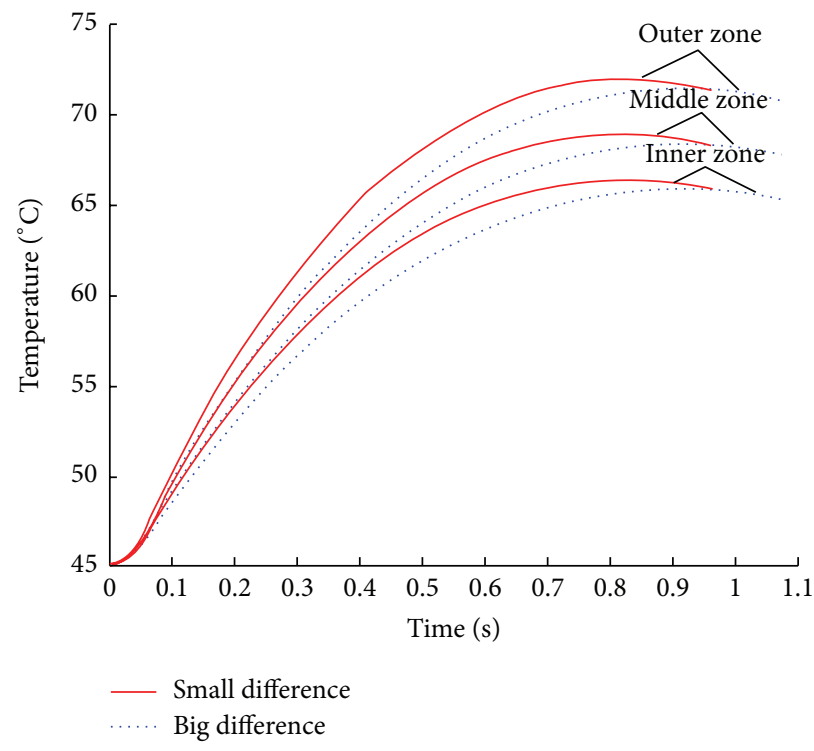

(b) Friction disk

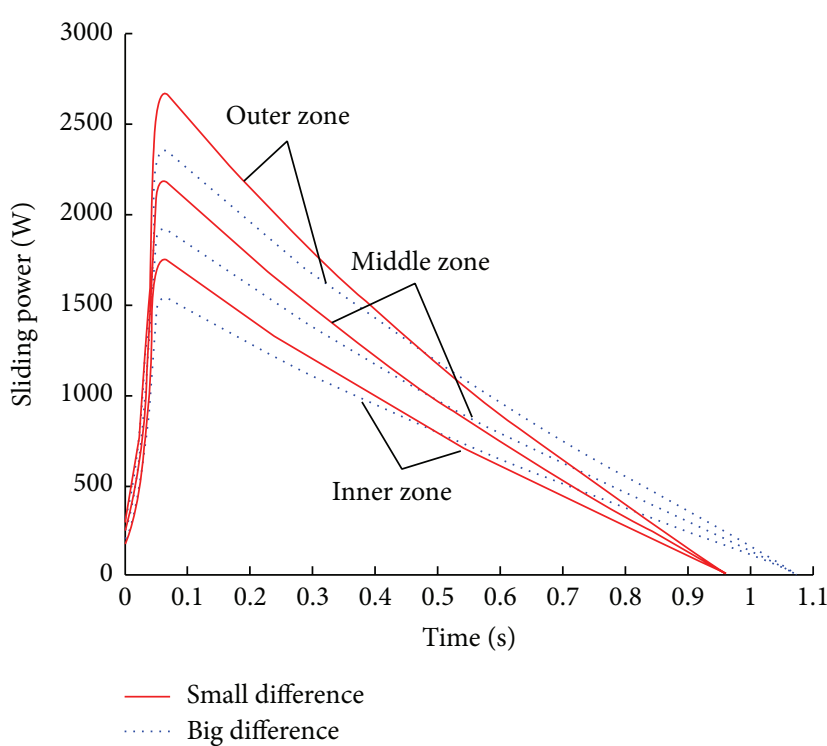

(d) Sliding power

Figure 8: Effect of difference between static and dynamic friction coefficient on temperature.

the temperature rise rate and maximum temperature of each zone of friction pair and lubricant increase.

4.7. Influence of Lubricant Flow. As shown in Figure 9, the change of lubricant flow only has small influence on the sliding friction power during the engagement of wet clutch; however, it certainly affects the temperature rise rate and maximum temperature of friction pair in asperity contact stage and has relatively large effect on the temperature rise characteristics of lubricant. With the increase of lubricant flow, the temperature rise rate and maximum temperature of outer and middle zones of friction pair will decrease, while the effect on the inner zone temperature is relatively small; the temperature drop of lubricant is most obvious. This is because larger lubricant flow will result in more lubricant flowing through the gap between friction pairs in unit time, larger thermal capacity of lubricant, larger convective heat exchange amount between friction pair and lubricant, and thus lower temperature rise rate and maximum temperature of friction pair and lubricant.

\section{Conclusions}

Numerical simulation of dynamic temperature rise characteristics of wet clutch has been conducted. Effects of parameters, such as engagement pressure, lubricant viscosity, friction lining permeability, surfaces roughness RMS, equivalent modulus, friction coefficient, and lubricant flow, on 


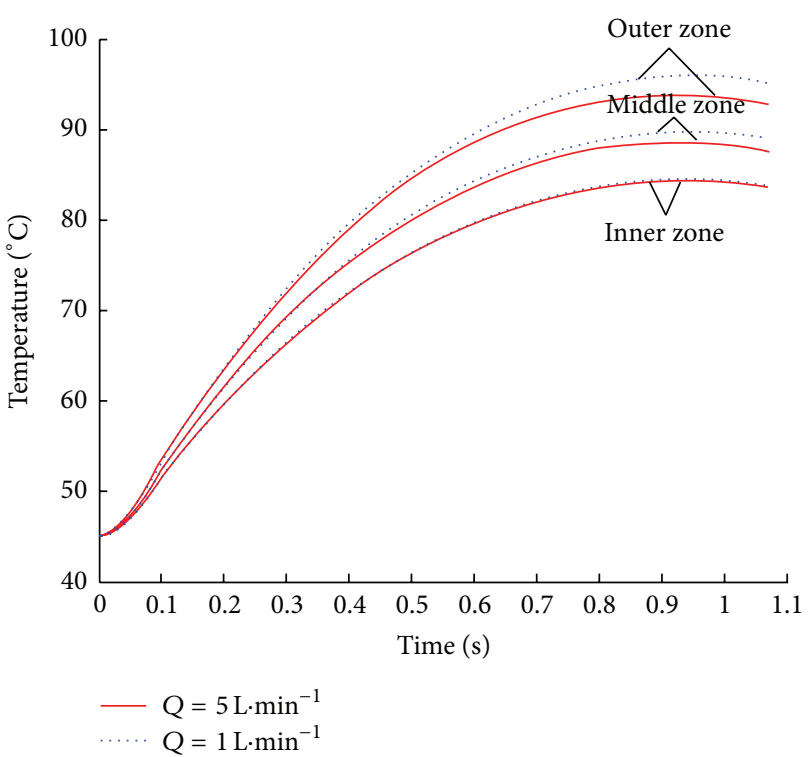

(a) Separator plate

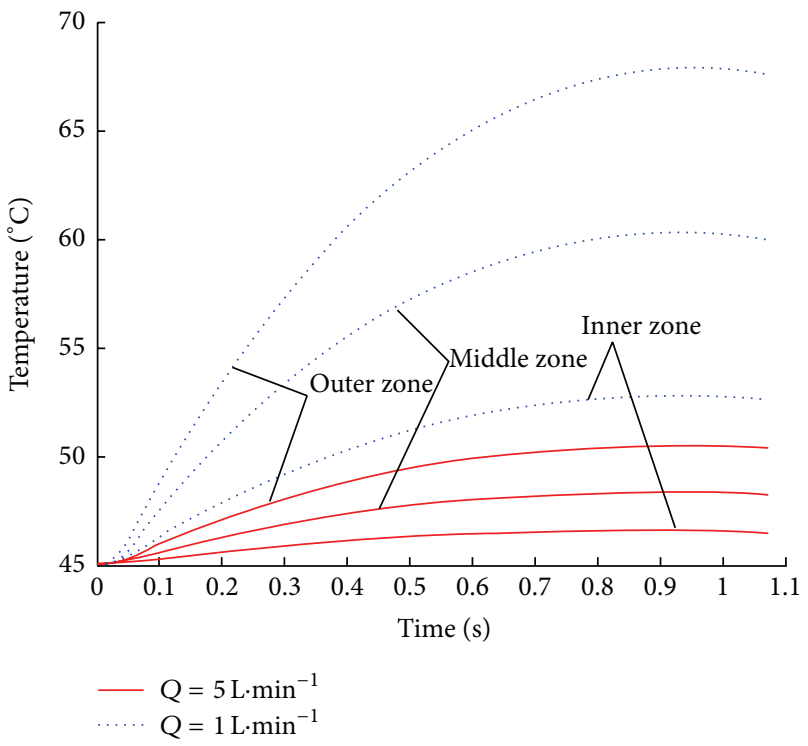

(c) Lubricant

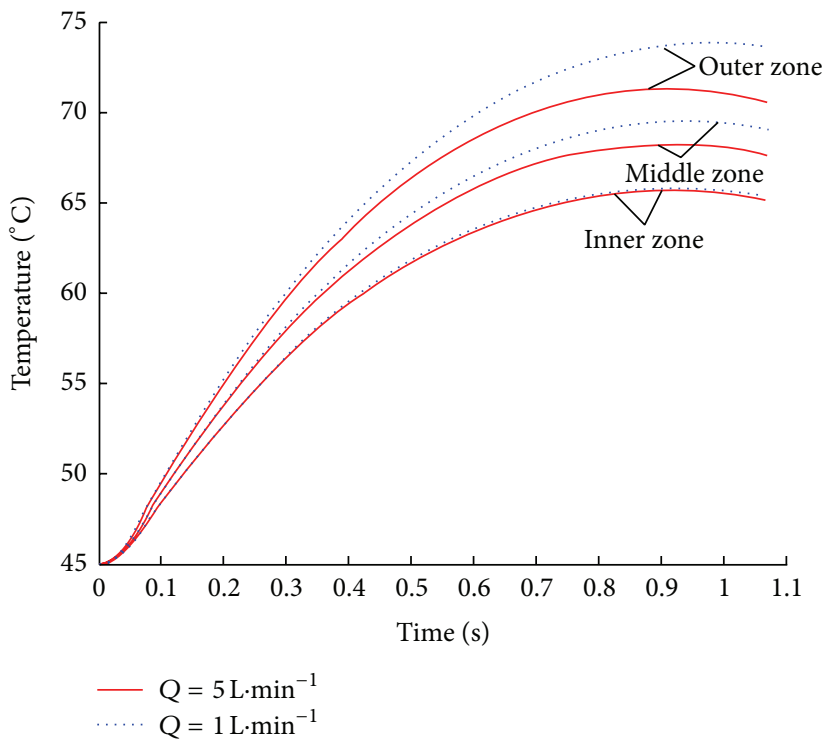

(b) Friction disk

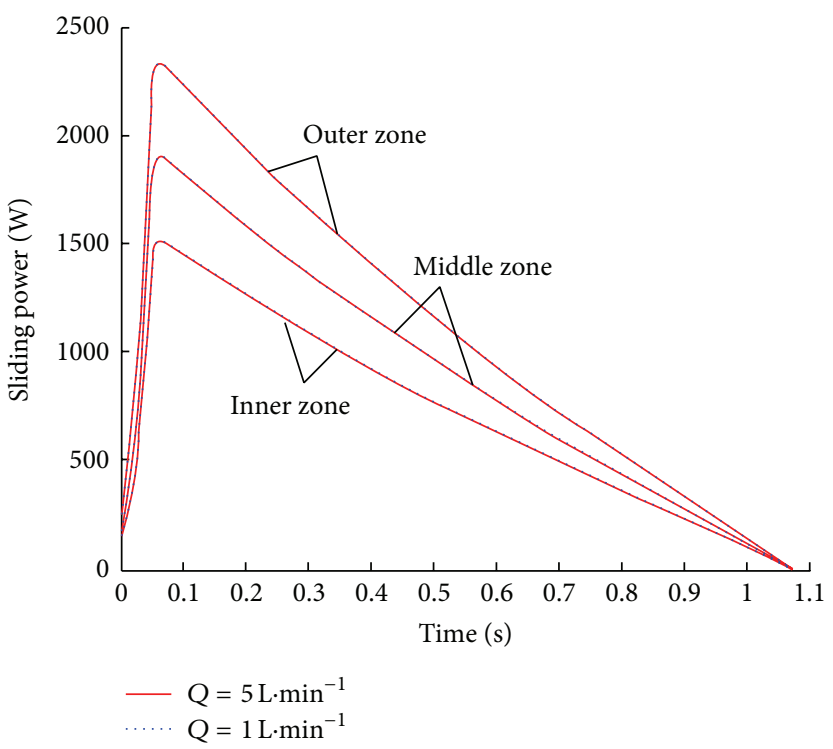

(d) Sliding power

FIGURE 9: Effect of lubricant flow on temperature.

temperature rise in wet clutch engagement were separately studied. Numerical results have led to the following conclusions:

(1) During the engagement process of wet clutch, the radial temperature distribution of separator plate, friction disk, and lubricant will rise along with the increase of radius.

(2) The changes in engagement pressure, lubricant viscosity, friction lining permeability, combined surfaces roughness RMS, equivalent elasticity modulus, difference between dynamic and static friction coefficients, and lubricant flow have important effects on the temperature rise characteristics of the engagement of wet clutch.
(3) With the increase of engagement pressure, the rise rate and maximum of temperature on different zone in friction disk, separator plate, and lubricant obviously increase.

(4) With the increase of lubricant viscosity, the rise rate and maximum of temperature on different zone in friction disk, separator plate, and lubricant slightly increase. However, the change of viscosity has significant effect on temperature of outer zone in friction pairs and lubricant film.

(5) With the increase of friction lining permeability, the rise rate of temperature in the squeezing and boundary lubrication stages during engagement has a significant increase, but the maximum temperature 
TABLE 1: Initial conditions for calculation.

\begin{tabular}{lc}
\hline Parameters & Value \\
\hline Inner radius of friction pairs $\mathrm{a} / \mathrm{m}$ & 0.064 \\
Outer radius of friction pairs $\mathrm{b} / \mathrm{m}$ & 0.085 \\
Thickness of friction lining $\mathrm{d} / \mathrm{m}$ & 0.001 \\
Surface roughness $\sigma / \mathrm{m}$ & $8.41 \times 10^{-6}$ \\
Permeability of friction lining $\Phi / \mathrm{m}^{2}$ & $4 \times 10^{-12}$ \\
Equivalent elastic modulus $E / \mathrm{Pa}$ & $2.7 \times 10^{8}$ \\
Density of roughness peak $\lambda / \mathrm{m}^{2}$ & $7 \times 10^{7}$ \\
Asperity tip radius $R / \mathrm{m}$ & $8 \times 10^{-4}$ \\
Initial film thickness $h_{0} / \mathrm{m}$ & $8.8 \times 10^{-4}$ \\
Viscosity of lubricant $\eta / \mathrm{Pa} \cdot \mathrm{s}$ & 0.0681 \\
Maximum engagement pressure $P_{0} / \mathrm{Pa}$ & $6 \times 10^{4}$ \\
Initial angular speed $\omega_{0} / \mathrm{rad} / \mathrm{s}$ & 1200 \\
Mass moment of inertia $\mathrm{I} / \mathrm{kg} \cdot \mathrm{m}^{2}$ & 0.56 \\
\hline
\end{tabular}

of friction pairs and lubricant almost remains the same.

(6) The combined surface roughness RMS and equivalent elasticity modulus have the same effect on the temperature rise characteristics. With the increase of them, the rise rate and maximum of temperature both rise obviously.

(7) With the decrease of the difference between dynamic and static friction coefficients, the rise rate and maximum of temperature significantly increase.

(8) The change of lubricant flow has an important influence on the rise rate of temperature in asperity contact stage and on the maximum temperature. And with the increase of lubricant flow, the lubricant temperature dramatically declines.

\section{Nomenclature}

$\begin{array}{ll}r: & \text { Radial variable }(\mathrm{m}) \\ t: & \text { Time }(\mathrm{s}) \\ \varepsilon: & \text { Compressive strain } \\ E: & \text { Elastic coefficient for compressive strain } \\ A_{n}: & \text { Oominal disk area }\left(\mathrm{m}^{2}\right) \\ h: & \text { Initial film thickness }(\mathrm{m}) \\ h_{0}: & \text { Permeability of friction lining }\left(\mathrm{m}^{2}\right) \\ \Phi: & \text { Thickness of friction lining }(\mathrm{m}) \\ d: & \text { Hydrodynamic pressure }(\mathrm{Pa}) \\ P_{h}: & \text { Viscosity of lubricant }(\mathrm{Pa} \cdot \mathrm{s}) \\ \eta: & \text { Average gap between friction pairs }(\mathrm{m}) \\ h_{T}: & \text { Combined surfaces roughness RMS } \\ \sigma: & \text { between friction pairs }(\mathrm{m}) \\ \operatorname{erf}(): & \text { Gauss error function } \\ \lambda: & \text { Asperity tip density } \\ \gamma: & \text { Asperity tip radius }(\mathrm{m}) \\ a: & \text { Inner radius of friction pairs }(\mathrm{m}) \\ b: & \text { Outer radius of friction pairs }(\mathrm{m}) \\ \phi_{f}, \phi_{f s}, \text { and } \phi_{r}: & \text { Patir-Cheng factors }[15,16]\end{array}$

$\omega_{\text {rel }}:$ Angular speed difference between friction pairs ( $\mathrm{rad} / \mathrm{s})$

$f_{c}:$ Dynamic friction coefficient, $f_{c}=0.13 \pm 0.008 \log \omega_{\text {rel }}$

$N_{u}$ : Nusselt number

$k_{f}$ : Thermal conductivity of lubricant $(\mathrm{W} /(\mathrm{m} \cdot \mathrm{K}))$

$\omega:$ Angular speed ( $\mathrm{rad} / \mathrm{s})$

$P_{s}:$ Pressure $(\mathrm{Pa})$

$h_{f}$ : Convective coefficient $\left(\mathrm{W} / \mathrm{m}^{2} \cdot \mathrm{K}\right)$

$q$ : Heat flux $\left(\mathrm{J} / \mathrm{m}^{2} \cdot \mathrm{s}\right)$

$c$ : $\quad$ Specific heat $(\mathrm{J} /(\mathrm{kg} \cdot \mathrm{K}))$

$\rho: \quad$ Density $\left(\mathrm{kg} / \mathrm{m}^{3}\right)$

$k$ : Thermal conductivity $(\mathrm{W} /(\mathrm{m} \cdot \mathrm{K}))$.

Subscript
A: Separator plate
B: Friction lining
o: Lubricant.

\section{Competing Interests}

The authors declare that they have no competing interests.

\section{Acknowledgments}

This project is supported by the National Natural Science Foundation of China (51205432) and Hunan Province Key Laboratory of Safety Design and Reliability Technology for Engineering Vehicle (KF1502).

\section{References}

[1] B. Depraetere, G. Pinte, W. Symens, and J. Swevers, "A two-level Iterative Learning Control scheme for the engagement of wet clutches," Mechatronics, vol. 21, no. 3, pp. 501-508, 2011.

[2] J.-L. Zhang, B. Ma, Y.-F. Zhang, and H.-Y. Li, "Simulation of thermal characteristic of wet shift clutch," Journal of Jilin University (Engineering and Technology Edition), vol. 41, no. 2, pp. 321-326, 2011.

[3] T. Deng, F. B. Hu, and D. Y. Sun, "An analysis on the thermoelastic instability of wet multi-disc clutch," Automotive Engineering, vol. 34, no. 10, pp. 918-922, 2012.

[4] T. M. Cameron, T. McCombs, and S. Tersigni, "Flash temperature in clutches," SAE Technical Paper 2005-01-3890, 2005.

[5] P. Zagrodzki and S. A. Truncone, "Generation of hot spots in a wet multidisk clutch during short-term engagement," Wear, vol. 254, no. 5-6, pp. 474-491, 2003.

[6] T.-C. Jen and D. J. Nemecek, "Thermal analysis of a wet-disk clutch subjected to a constant energy engagement," International Journal of Heat and Mass Transfer, vol. 51, no. 7-8, pp. 1757-1769, 2008

[7] R. A. Tatara and P. Payvar, "Multiple engagement wet clutch heat transfer model," Numerical Heat Transfer, Part A: Applications, vol. 42, no. 3, pp. 215-231, 2002.

[8] J. Y. Jang, M. M. Khonsari, and R. Maki, “Three-dimensional thermohydrodynamic analysis of a wet clutch with consideration of grooved friction surfaces," Journal of Tribology, vol. 133, no. 1, Article ID 011703, 2011. 
[9] W. Yang, G.-D. Lu, H.-S. Lv, Y. Liu, and L.-H. Lin, “Thermomechanical coupling analysis of dual-steel-disc of wet multidisk clutch," Journal of Chongqing University, vol. 34, no. 9, pp. 26-32, 2011.

[10] J.-L. Zhang, B. Ma, Y.-F. Zhang, and H.-Y. Li, "Study on the factors affecting temperature field and stress field of the wet shift clutch," Transaction of Beijing Institute of Technology, vol. 30, no. 6, pp. 660-664, 2010.

[11] S. Natsumeda and T. Miyoshi, "Numerical simulation of engagement of paper based wet clutch facing," Journal of Tribology, vol. 116, no. 2, pp. 232-237, 1994.

[12] E. J. Berger, F. Sadeghi, and C. M. Krousgrill, "Analytical and numerical modeling of engagement of rough, permeable, grooved wet clutches," Journal of Tribology, vol. 119, no. 1, pp. 143-148, 1997.

[13] Y. Yang, R. Lam, and T. Fujii, "Prediction of torque response during the engagement of wet friction clutch," SAE Technical Paper 981097, 1998.

[14] G. Chen, B. Kevin, and C. Edward, "Real time virtual temperature sensor for transmission clutches," SAE Technical Paper No. 2011-01-0230, SAE International, 2011.

[15] N. Patir and H. S. Cheng, "Application of average flow model to lubrication between rough sliding surfaces," Journal of Lubrication Technology, vol. 101, no. 2, pp. 220-230, 1979.

[16] N. Patir and H. S. Cheng, "Prediction of the bulk temperature in spur gears based on finite element temperature analysis," A $S$ L E Transactions, vol. 22, no. 1, pp. 25-36, 1979. 


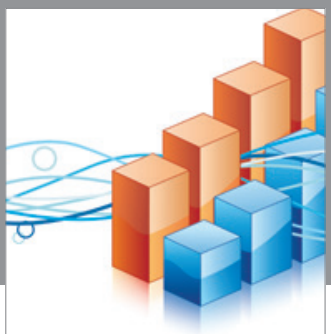

Advances in

Operations Research

vatem alat4

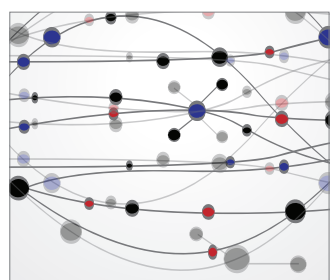

\section{The Scientific} World Journal
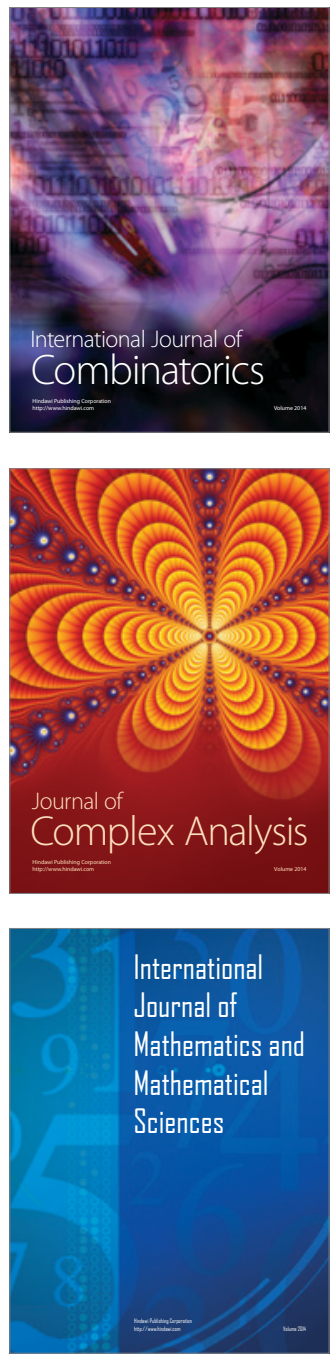
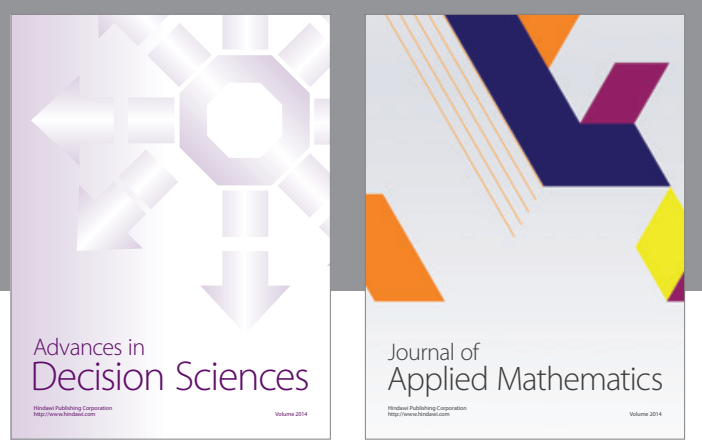

Algebra

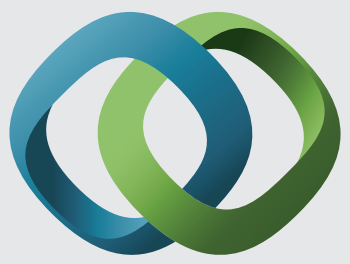

\section{Hindawi}

Submit your manuscripts at

http://www.hindawi.com
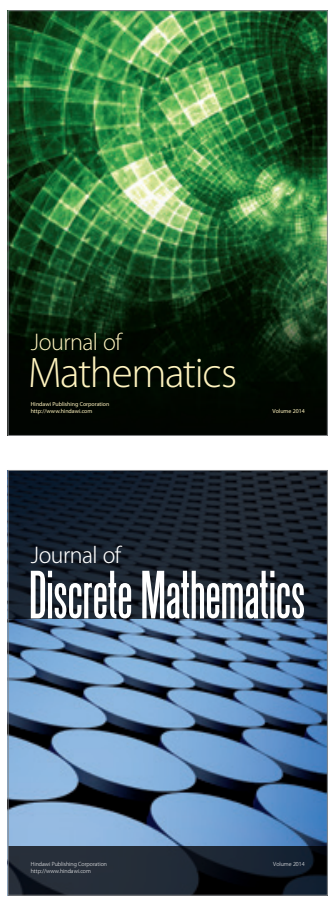

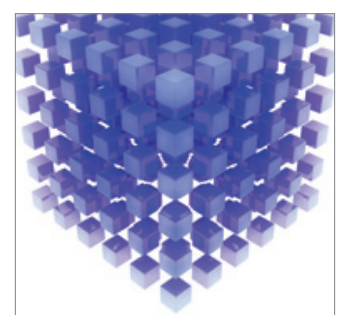

Mathematical Problems in Engineering
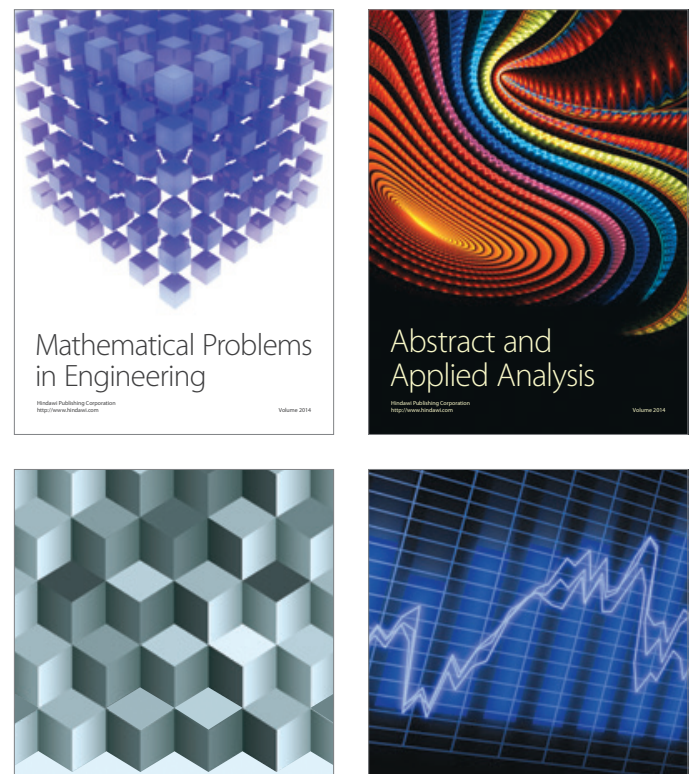

Journal of

Function Spaces

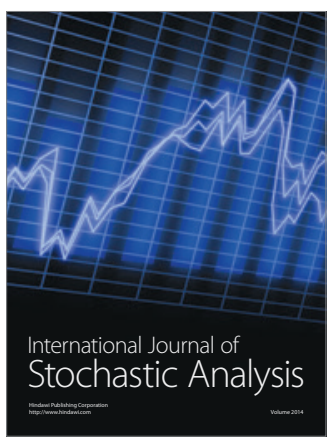

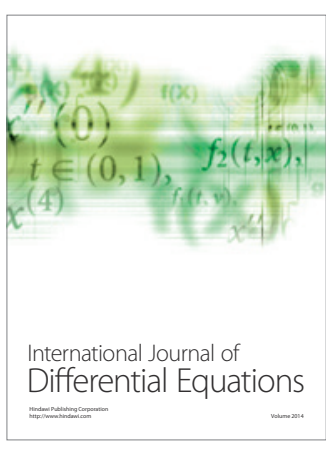
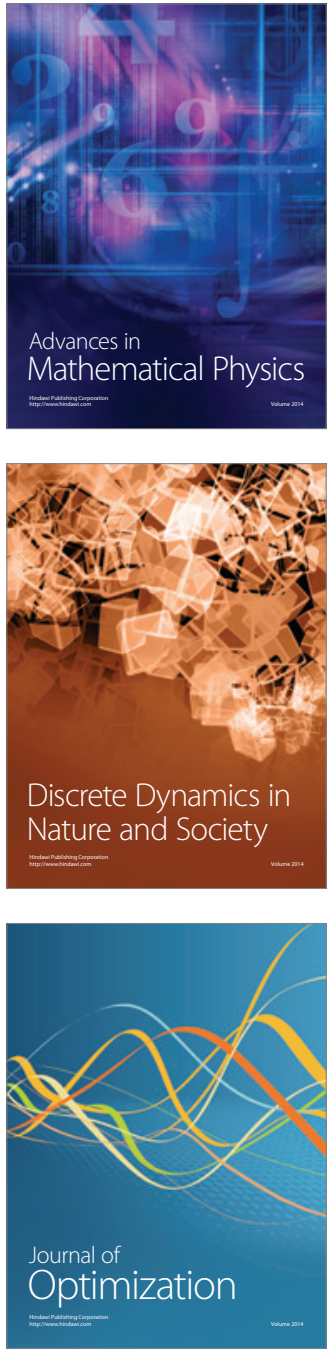